\title{
LEVINAS: MITO-LOGOS E A POSSIBILIDADE DE UM SENTIDO ÉTICO
}

Marcelo Fabri*

SINTESE - O artigo aborda a crítica de Levinas ao predomínio do Logos no pensamento ocidental e investiga de que maneira a resistência ética à Totalidade só pode ser entendida se considerarmos igualmente a sua critica à noção de participação mística, no sentido de Levy-Brühl. A tese de fundo e que a visão negativa do discurso ontológico ocidental e, no fundo, uma critica as relaçöes entre este discurso e a esfera do Mito, e esta critica que possibilita um Logos irredutível ao primado da ontologia e da Totalidade. Esta possibilidade se descreve por uma constante tensão entre o ético e o ontológico.

PAI.AVRAS-CHAVE - Mito. Logos. Totalidade. Ética. Sentido. Ontologia.
ABSTRACT - In this paper, we discuss Levina's attack on the predominance of the Logos in Westerns thought. In addition to this, we try to demonstrate that the ethical resistance to the Totality can be understood only if we take into account Levina's criticism of Levy-Bruhl's notion of mystical participation. Thus, our main thesis is the one according to which the negative outlook implied by the Western ontological discourse is, at bottom, a criticism of the relations between such a discourse and the sphere of the Myth. This criticism itself brings, as a result, the emergence of a Logos which is irreducible to the preeminence of both the ontology and the Totality. This emergence unfolds through a constant tension between the ethical and the ontological.

KEY WORDS - Myth. Logos. Totality. Ethics. Meaning. Ontology.

A obra de Emmanuel Levinas pode ser caracterizada, em certo sentido, como o esforço para pensar a noção de filosofia como resistência ao modelo de verdade que imperou no Ocidente desde Parmênides, sugerindo que esse modelo foi quase sempre uma variação sobre um mesmo tema, sobre uma mesma melodia interminável, executada magistralmente desde a aurora do pensamento grego até os mais altos vôos da especulação hegeliana e das profundas análises heideggerianas sobre o sentido esquecido do ser, em uma das mais grandiosas obras filosóficas do século xx, intitulada Ser e Tempo. ${ }^{1}$ Em Totalidade e Infinito (1961), Levinas propõe a ruptura com a primazia do discurso que se celebrizou no Ocidente como discur-

* Doutor. Professor da Universidade Federal de Santa Maria (UFSM).

1 HEIDEGGER, Martin. Sein und Zeit (1927). Tübingen: Max Niemeyer Verlag, 1979.

\begin{tabular}{|l|l|l|l|l|l|} 
VERITAS & Porto Alegre & v. 44 & n. 2 & Junho 1999 & p. 285-296 \\
\hline
\end{tabular}


so do Mesmo, como subordinação dos seres ao sentido que lhes era conferido pela totalidade, ${ }^{2}$ pelo prestígio da unidade perfazendo-se mediante a superação do múltiplo em favor do idêntico e realizando-se na valorização da estabilidade da terra firme, na supremacia do Ser, numa palavra, no primado da ontologia.

Desde seus primeiros escritos, Levinas apresenta o desafio de buscar uma saída da ontologia. Para tanto, é preciso vencer a neutralidade do ser impessoal (il y a), isto é, a violência do anônimo que oprime o existente e da qual este busca uma saída, uma evasão. ${ }^{3} \mathrm{O}$ anonimato do ser é para Levinas algo bem próximo à participação mística descrita por Lévy-Brühl, ${ }^{4}$ pois a mentalidade primitiva e a experiência do sagrado representam a despersonalização do existente diante da neutralidade do ser impessoal. ${ }^{5}$ Assim, a filosofia possibilitou aquilo que Levinas chama separação, vale dizer, o fim da comunhão mística com as espécies. ${ }^{6}$ Para criticar a participação e o paganismo, Levinas precisa ele próprio de uma valorização do saber racional e da teoria. Como escapar à ambigüidade de um elogio e de uma crítica à filosofia? Não será porque a outra face do logos encontra-se no próprio Mito? Na nossa perspectiva, é a crítica à participação que sustenta a crítica levinasiana ao saber, à razão como totalidade neutra e impessoal. Assim, a resistência ao Mito, tantas vezes reiterada em seus escritos, representa a possibilidade de um logos irredutível ao jogo do ser, ao predomínio da totalidade, vivendo de uma constante tensão entre o ético e o ontológico. ${ }^{7}$ Por conseguinte, a crítica ao Mesmo se dirige ao movimento mito-poético da ontologia, que por sua vez comanda a supremacia do discurso racional e, ao mesmo tempo, a totalidade como

2 "A face do ser que se mostra na guerra fixa-se no conceito de totalidade, que domina a filosofia ocidental. Os indivíduos reduzem-se ai a portadores de formas que os comandam, sem que eles saibam. Os indivíduos vão buscar nessa totalidade o seu sentido (invisivel fora dela). A unicidade de cada presente sacrifica-se incessantemente a um futuro chamado a desvendar o seu sentido objetivo. Porque só o sentido último é que conta, só o último ato transforma os seres neles próprios. Eles serão o que aparecem nas formas, já plásticas, da epopéia" (Totalité et Infini. Essai sur l'Extériorité. Martinus Nijhoff, 1971, biblio. Essais, p. 6).

3 Cf.: LEVINAS, E. De l'évasion (1935). Édition annotée par Jacques Rolland. Montpellier: Fata Morgana, 1982. Categoria fundamental da obra levinasiana, a evasão expressa, desde os primeiros es critos, a situação dramática do existente às voltas com ameaça do ser, isto é, com o seu anonimato. Trata-se, de modo geral, de um discurso sobre a necessidade de saída das alternativas da ontologia, do ser e do não-ser, ou ainda, do topos grego. Esta tentativa será, de resto, o desafio filosófico de todo o percurso filosófico de Levinas. Cf. também: De P'existence à P'existant (1947). Paris: Vrin, 1986. Neste livro, o il y a é o ser impessoal destituído de dádiva ou generosidade, pois sua presença sufocante indica apenas uma neutralidade inumana.

4 Sobre este assunto, ver o artigo de Levinas "Lévy-Brühl e a filosofia contemporânea" (1957); In: LEVINAS, E. Entre nós: ensaios sobre a alteridade. Tradução de Pergentino S. Pivatto (coord.). Petrópolis: Vozes, 1997, p. 66-83.

5 "Na participação mistica, essencialmente distinta da participação platônica em um gênero, a identidade dos termos se perde. Eles despojam-se daquilo que constitui a sua própria substancialidade" (Levinas, E. De l'existence à l'existant, p. 99).

6 "O ménto imperecivel do 'admirável povo grego' e da própria instituição da filosofia terá consistido exatamente em ter substituído a comunhão mágica das espécies e a confusão das ordens distintas por uma relaçâo espiritual em que os seres permanecem no seu posto, mas comunicam entre si [...]. O ser cognoscente permanece separado do ser conhecido" (Totalité et Infini, p. 39-40).

7 A esse respeito, Cf.: FABRI, Marcelo. Desencantando a Ontologia: subjetividade e sentido ético em Levinas. Porto Alegre: EDIPUCRS, 1997. 
categoria fundamental do modo de pensar do Ocidente. Assim, uma tal crítica só pode realizar-se como tensão entre a defesa da língua grega e a denúncia das armadilhas inerentes à "sabedoria grega." Mostrar que é possivel e necessário separar as duas coisas é talvez o desafio maior da filosofia de Levinas. ${ }^{8}$

\section{Totalidade e violência}

A filosofia tem o mérito de ter rejeitado a "participação mística" inerente ao mundo do mito, isto é, a participação dos seres nas redes invisíveis que a sacralidade politeísta implicava, abrindo desta sorte vias para uma valorização da linguagem como logos e epistême. ${ }^{9}$ No entanto, esta liberdade conquistada vai unirse a um outro tipo de violência, a saber, o poder do conhecimento que degenera em manipulação e domínio sobre os seres em sua singularidade. $\mathrm{O}$ conceito de totalidade, fundamental para se compreender a história do próprio Ocidente, é o topos em que se fixa o conceito de ser, não como paz, não como respeito aos seres em sua liberdade, mas como guerra e conflito, e é precisamente a partir da dimensão política de tal pensamento que a moral pode ganhar uma fundamentação e uma confirmação. Neste caso, a evidência da totalidade torna-se algo irrefutável. Existe uma outra via? Outro caminho? Em Totalité et Infini, lemos:

“A consciência moral só pode suportar o olhar trocista do político se a certeza da paz dominar a evidência da guerra. Uma tal certeza não se obtém por simples jogo de antíteses. A paz dos impérios saidos da guerra assenta na guerra e não devolve aos seres alienados a sua identidade perdida. É necessária uma relação originária e original com o ser." 10

Nesse sentido, parece-nos possível dizer que, em Levinas, uma coisa é a língua grega, língua da ciência e da filosofia, da possibilidade do discurso coerente e racional, língua que ele próprio faz questão de utilizar em seus escritos, outra coisa é a "sabedoria grega", vinculada de algum modo aos acontecimentos que marcaram a nossa história repleta de guerras e infortúnios, de triunfos e de fiascos, sabedoria às voltas com a sedução do poder e da política, com a justificativa da guerra e a idolatria do Estado. Isso porque a razão, ao reduzir o Outro ao Mesmo, tende sempre a reduzir e a neutralizar a alteridade em favor da soberania do

8 Este é o questionamento que Derrida dirige a Levinas em "Violence et Métaphysique" ( $L$ 'écriture et la difference. Paris: Seuil, 1967) acerca de Totalidade e Infinito e, mais recentemente, Paul Ricoeur em Autrement Lecture d'Autrement qu'être ou au-delà de I essence d'Emmanuel Levinas (Paris: PUF, 1997). Derrida se pergunta se a escrita levinasiana pode prescindir da ontologia para justificarse como discurso ético; Ricoeur, por sua vez, se indaga sobre a possivel repetição da ontologia presente em Autrement qu'être, vale dizer, sobre um modo pós-ético de re-dizer a própria tradição a partir de uma terminologia que não cessa de recorrer a temas como bondade, Infinito, eleidade e Nome de Deus (p. 35-36).

9 "O esquema da teoria, em que a metafisica se reencontrava, distinguia-se de todo o comportamento extático. A teoria exclui a implantação do ser cognoscente no ser conhecido, a entrada no Além, por êxtase; permanece conhecimento, relação. É verdade que a representação não constitui a relação original com o ser, mas é privilegiada, precisamente como a possibilidade de evocar a separação do Eu" (Totalité et Infini, p. 39).

Ibid. 
ato de conhecer. O Outro torna-se tema e objeto. Para Levinas, a ontologia como inteligência dos seres é uma filosofia da violência. ${ }^{11}$

Conseqüentemente, a recusa do modo mítico de existir não é apenas a manifestação de uma espiritualidade religiosa de tipo judaica, mas exercício filosófico necessário à própria crítica, à ontologia e à totalidade. Em outros termos, pensamos que a crítica à razão e ao primado do Mesmo em relação ao Outro permanece incompreensivel e injustificável sem a explicitação da resistência que Levinas manifesta em relação à experiência do divino como envolvimento no sagrado ou como participação no seu fascínio.

\section{O fim da participação: a verdade para além da totalidade}

A noção levinasiana da verdade passa por uma constante crítica à participação dos indivíduos no interior da totalidade e no sentido da história universal, mas também e sobretudo no fascínio do contato com o numinoso e com o sagrado. A estrutura do eu supõe a separação, vale dizer, a vida interior como desenraizamento e não-participação. ${ }^{12}$

Toda a segunda Seção de Totalidade e Infinito é marcada por uma fenomenologia do psiquismo humano como fruição, vida interior, egoísmo estrutural. Uma tal fenomenologia irá descrever situações concretas que dispensam a referência à totalidade. A separação é a vida do psiquismo em uma espécie de independência em relação ao enraizamento prévio no ser, independência esta que tornará possível a verdade como algo distinto da união entre o cognoscente e o conhecido. A separação é necessária para que a verdade possa acontecer como revelação, que por sua vez só é possível como ruptura da participação no ser. Toda subjetividade cognoscente supõe o eu (moi) como interioridade não reconhecida, capaz de ver sem ser vista, condição que o mito de Giges expressa de modo exemplar.

Como pode o eu existir separadamente? Para Levinas, é pela fruição que isso se torna possivel. Antes mesmo de se converter em objeto de nossa representação, ${ }^{13}$ o mundo se oferece a nós como alimento, como alegria e prazer da "boa

11 Esta violência, presente na indiferença do Mesmo em relação ao Outro, encontra-se também em Heidegger, para quem a obediência ao ser é determinante para a relação ao Outro. É neste sentido que a ontologia conduz ao poder e à tirania. "Tirania que não é a extensão pura e simples da técnica a homens reificados. Ela remonta a "estados de alma" pagãos, ao enraizamento no solo, à adoração que homens escravizados podem votar aos seus senhores. O ser antes do ente, a ontologia antes da metafísica - é a liberdade (mesmo que fosse a da teoria) antes da justiça. É um movimento dentro do Mesmo antes da obrigação em relação ao Outro" (Totalité et Infini, p. 38).

12 Cf.: Totalité et Infini, p. 54. Sobre a separação, Cf.: BAILHACHE, Gérard. Le sujet chez Emmanuel Levinas: fragilité et subjectivité (Paris: PUF, 1994, p. 73 seg.). Para esse autor, a separação levinasiana significa uma rejeição do paganismo. Nesse sentido, é "a separação que permite que a busca da verdade venha a ocorrer, a produzir-se nessa relação entre o Mesmo com o Outro, ao passo que a participação nos abandona no ser, sem mais nem menos [...] Em nome da separaçāo, Levinas recusa o enraizamento" (p. 73-74). Ver também: LIBERMAN, J. La séparation chez Levinas. Revue de Métaphysique et de Morale. Paris: Armand Colin Editeur, 1981, n. 4, oct.-déc. 1981. Segundo Liberman, "o Mesmo não é uma totalidade cuja coincidência consigo mesmo poderia pré-existir à sua entrada em relação com a exterioridade; ele é antes um inacabamento primordial, uma unicidade não totalizada que recebe sua densidade a partir de uma relação primordial e inelutável com a exterioridade - um Outro que não é um outro Mesmo, uma força que não é um poder" (p. 438).

Cf. ibid., seção II, p. 111 seg. 
sopa", do trabalho, das caminhadas, das conversas, do ar que respiramos, da água refrescante num dia de verão. Antes de manipularmos e manusearmos os objetos, fruímos deles, como se eles fossem objetos de puro gozo e prazer. O conteúdo dos alimentos não é algo representado, mas vivido. A intencionalidade da fruição é um viver de...

Por que e como é possivel falar em verdade? Em Levinas, a verdade não se identifica com o ideal clássico de adequação, nem mesmo com o desvelamento do ser. A dimensão de interioridade, garantida por uma relação em que os termos nunca se dissolvem, traz a possibilidade de uma revelação. Assim:

" $A$ experiência absoluta não é desvelamento, mas revelação: coincidência do expresso e daquele que exprime, manifestação por isso mesmo privilegiada de Outrem, manifestação de um rosto para além da forma."14

Que tipo de relação existe entre a separação e o conceito levinasiano de verdade? Ora, a originalidade da noção de verdade presente em Totalidade e Infinito é a não-subordinação do verdadeiro à participação no ser. A separação indica uma forma de existência que se encontra acima do ser, e é por isso que se pode dizer que a verdade não se subordina a uma relação que implica assimilação, objetivação e participação. Para Levinas, a verdade é um acontecimento mais fundamental que a teoria, pois a teoria é apenas um modo de relação com a exterioridade. ${ }^{15}$ É a exterioridade que será o guia da busca da verdade, mas a sua possibilidade não se define pela totalidade e sim pela idéia de Infinito, isto é, pela inadequação por excelência. ${ }^{16}$

Se por um lado a separação implica a vida interior como fruição, psiquismo ou alma, a exterioridade permanece sempre do lado de um absolutamente outro, vale dizer, daquilo que não se encontra à medida da alma. Por conseguinte, a verdade levinasiana transcende a reminiscência, que permanece implícita em nossa tradição filosófica desde Platão, pois é na relação à alma que a identidade do ser se afirma e domina de modo inquestionável. ${ }^{17}$

Para esta tradição, a Alma é apenas um jogo do próprio Ser. Afirma Levinas: “A Alma é, para Platão, da mesma natureza que as Idéias, e em Plotino uma hipóstase. Em Hegel, o espírito subjetivo - como alma, como consciência e finalmente como sujeito - é imprescindivel na História do Espírito ou do Ser. Em Hei-

14 Ibid., p. 61 (grifo do autor).

15 Ibid., p. 55.

16 "A idéia do infinito não é uma intencionalidade da qual o Infinito seria o objeto. A intencionalidade é um movimento do espírito adaptado ao ser. Ela visa. Ela vai em direção a um tema. No tema, o ser se acomoda à vontade. O ser é o 'tematizável' por excelência, o proponivel, o tético. Mas a intencionalidade que é a abertura do pensamento ao tema não deborda este tema. Ela não consiste em pensar mais do que nela é pensado. O noema se delineia perfeitamente na noese. A idéia do infinito consiste precisamente e paradoxalmente em pensar mais do que é pensado. mas conservando-o no entanto em sua desmesura em relação ao pensamento. A idéia de infinito consiste em apreender o inatingivel, garantindo-lhe no entanto seu status de inatingivel" (LEVINAS, E. Transcendance et Hauteur. In: Cahier de I Herne, Emmanuel Levinas. Paris: Editions de l'Heme, 1991, p. 103).

17 Ver a esse respeito o estudo "La pensée de l'être et la question de l'autre"; In: De Dieu qui vient à Pidée. Paris: Vrin, 1992, p. 173-188. 
degger, o homem é o pastor do Ser."18 Ora, a importância filosófica desta afirmação é esta: "A filosofia é essencial ao ser enquanto ser. O conhecimento do ser que se produz na alma ou no homem - a verdade - é um acontecimento primordial do próprio ser." $19 \mathrm{O}$ ser, de algum modo, liga-se a um processo de desvelamento. $\mathrm{O}$ ser pode brilhar na medida em que se torna o verdadeiro, e isso porque ele se encontra à medida do humano e, conseqüentemente, do pensamento. Levinas compara o acontecimento do Mesmo na obra da verdade como a pedra filosofal da alquimia filosófica.

A atividade teórica, louvada a princípio como possibilidade de vencer a comunhão mistica, é ela própria criticada a partir de uma espécie de sedução que se assemelha a esta mesma comunhão. ${ }^{20}$ Para Levinas, o grande mito da filosofia é a idéia de uma consciência capaz de legislar sobre todas as coisas, capaz de reconciliar a diferença com a identidade na universalidade do Mesmo. ${ }^{21}$ Como sair deste mito, que compreende toda inteligibilidade como algo inseparável da medida do Mesmo? Mais: por que é preciso dele sair? Ora, o aspecto prático e teórico que este mito envolve vai além do registro específico da filosofia. $\mathrm{O}$ poder inerente ao Estado Moderno, a força histórica da sociedade industrial e dos impérios tecnológicos e monetários podem separar-se desta saga mítica intrínseca ao modo de pensar do Ocidente? O valor do humano pode ser extraído desta hipervalorização do Mesmo? A essas perguntas, Levinas responde pela negativa.

O fim da participação é o abalo da atividade englobante e sintética da filosofia ocidental, é o questionamento da relação profunda entre verdade e ontologia, entre filosofia e identidade do ser. Mas, como questionar o exercício da liberdade do saber? Pode a espontaneidade da certeza, que se manisfesta no saber, ser posta em questão?22 A liberdade, que o conhecimento do Mesmo requer e possibilita, justifica-se por si mesma, desobriga-nos em relação a um exame sobre as implicações éticas de sua realização?

$\mathrm{O}$ afastamento da comunhão mística, possibilitada pelo acontecimento da teoria, não tem como evitar a egologia inerente à razão. A razão teórica é neutra e impessoal. Assim, é a relação ética ao outro que permite questionar o caráter egológico da razão.

\section{O alvorecer de uma humanidade sem mitos}

Em Levinas, o Desejo da exterioridade é um excesso, uma possibilidade de se pensar mais do que a capacidade da consciência intencional permite. Em outros

18 Transcendance et Hauteur, p. 98.

19 Ibid. Grifo do autor.

20 A esse propósito, Derrida afirma: "A cumplicidade entre a objetividade teórica e a comunhäo mística, tal será o verdadeiro alvo de Levinas. Unidade pré-metafísica de uma só e mesma violência. Alternativa modificando sempre o mesmo enclausuramento do outro" (Violence et Métaphysique, p. 130). Sobre esse assunto, cf. também: WESTPHAL, Merold. Levinas's teleological suspension of religious. In: Ethics as first Philosophy. the significance of Emmanuel Levinas for Philosophy, Literature and Religion (Edited by PEPERZAK, Adriaan T. New York and London: Routledge, 1995, p. 153-160).

21 Ibid., p. 99.

22 Cf. Totalité et Infini, p. 90. 
termos, ao medir a infinidade do infinito, o Desejo é uma espécie de desmesura. 0 Desejo é uma aspiração animada pelo próprio desejável, uma "revelação", porquanto nasce sempre de seu "objeto". A separação não implica a busca de um preenchimento, de uma repleção, pois, em certo sentido, o ser separado não tem falta de nada. O Desejo do outro não é a nostalgia do que se perdeu, mas linguagem pela qual o eu fala ao outro, sem nele se abismar ou a ele se unir.

A separação radical dos interlocutores é, na linguagem, o pressuposto de toda transcendência, de toda revelação do outro a mim. A linguagem se coloca na transcendência porquanto nela não há comunidade entre os termos, mas traumatismo do espanto, revelação trazida pelo absolutamente estrangeiro. Tal relação é a própria recusa da objetivação como situação privilegiada para se conceber a verdade. A linguagem é a relação com uma nudez, como uma presença despida de formas e, conseqüentemente, inapreensivel mediante categorias. A relação ao outro implica o ser visado por um olhar (visage), por uma fome que põe em questão minha feliz e inocente posse do mundo pela fruição. $\mathrm{O}$ mundo comum começa aí, quando ofereço coisas minhas a outrem, quando concedo que os objetos de minha posse adquiram a condição de um mundo comum. $\mathrm{O}$ acolhimento do outro vem antes de toda tipologia, de toda caracteriologia e de toda classificação. Mais ainda: não se pode revestir a presença de um visage com as formas da arte e do conhecimento. Tampouco a participação, capaz de encetar uma relação com o divino e o transcendente, poderia ser o modelo da transcendência levinasiana.

É certo que podemos realizar pesquisas, estudos e experiências sem uma preocupação explícita ou primeira com os destinos do outro e de todos os outros. O conhecimento é uma atividade que envolve solidão e separação, que coloca 0 $e u$ na condição de criatura capaz de contestar a existência de seu criador. $\mathrm{O} e u$, na separação, vive a experiência do ateísmo, podendo ou não abrir-se a um ato de fé e às promessas da religião. Do mesmo modo, o eu separado pode fazer também a experiência da dúvida filosófica, dúvida esta que teria como conduzi-lo aos domínios da verdade e da razão. Mas Levinas insiste em que, sem a presença da exterioridade, o discurso teórico não poderia começar. Por conseguinte, o discurso implica o debate entre os interlocutores, por meio do qual alguém sempre pode prestar auxílio a seu próprio discurso, sempre pode exercitar a palavra como expressão e começo. Aqui, sobretudo, o sentido da linguagem, como relação entre interlocutores que se encontram separados, supõe a transcendência como assimetria e maestria, como possibilidade de se receber um ensinamento novo.

Por que há ensino? Por que há saber objetivo? Para Levinas, toda objetivação supõe o oferecimento de um mundo ao outro, isto é, a abolição de uma apropriação. Assim:

"A generalidade do Objeto é correlativa da generosidade do sujeito que vai para Outrem, para além da fruição egoísta e solitária, e faz aparecer, por conseguinte, na propriedade exclusiva da fruição, a comunidade dos bens desse mundo."23

A universalidade da linguagem começa quando as coisas que são minhas são oferecidas a outrem e passam, deste modo, à comunidade da generalização. A 
linguagem torna possível, assim, uma posse comum, uma partilha que faz a passagem do particular ao geral. A linguagem, em sentido levinasiano, pressupõe 0 acolhimento do Outro pelo Mesmo.

Se a separação é necessária para que os termos da relação não sejam assimilados por um pensamento sinóptico, é preciso compreender que, na sua condição de separado, o eu corre o risco de abismar-se no mundo nebuloso de uma existência impessoal. A idéia de Infinito supõe uma quebra da participação no fascínio do numinoso, uma contestação da experiência do sagrado como modelo da transcendência ética. ${ }^{24}$ A relação com o infinito é a relação a Deus sem participação, sem apelo à idéia de ser e à mística. O infinito é um traumatismo que traz uma dissolução das experiências místicas com o divino, mas esta possibilidade não se encontra garantida pela objetivação ou pelo conhecimento do objeto. A relação ao Outro está na origem de toda objetivação. Certo. Mas a objetivação que esta relação possibilitou não suspende o perigo da participação, de uma queda no mundo do mito e, por conseguinte, da totalidade. É por isso que a idéia de infinito é o alvorecer de uma humanidade sem mitos, ${ }^{25}$ isto é, de uma humanidade no sentido pleno da palavra. Não será porque, do mesmo modo que o eu ateu pode entregarse a uma experiência numinosa e perder-se, deste modo, numa rede de relações impessoais, ele também pode alienar-se numa elevação cada vez maior de seu poderio enquanto Mesmo, enquanto identidade soberana que ignora outrem? Em Levinas, a relação a Deus, ao absoluto é, curiosamente, uma dessacralização do sagrado, uma crítica aos vínculos com o numinoso, mas também uma desalienação do Mesmo enquanto prisioneiro de sua própria violência, de seu próprio império. Esta dessacralização se expressa mediante as idéias de traumatismo, de altu$r a$, de ensinamento, e não com a busca de participação e de união ao transcendente e ao ser. Trata-se de uma suspensão da participação que instaura, por sua vez, uma relação irredutível a toda objetivação e a toda tematização. Assim, a humanidade sem mitos de que fala Levinas não se caracteriza pela terra devastada e pela noite de um mundo sem sentido, mas pelo ponto onde o humano começa, onde a palavra humanidade significa. Este começo é a negação do mundo sem rosto do mito, é o surgimento da racionalidade a partir da ética ou, como insiste Levinas, da justiça feita aos homens. Por conseguinte, a relação face a face implica o primado da ética sobre a ontologia, mas também sobre os contatos com qualquer realidade mítica e impessoal, estética ou numinosa. Que é o logos para Levinas? Ele é uma vigilia permanente entre duas possibilidades que se comunicam: a prisão dos mitos e a violência inerente à razão. A fonte e o sentido da palavra profética não se encontram numa experiência de fé, mas na superação da solidão de uma experiência filosófica. Por quê?

24 "Na dimensão de altura em que se apresenta a sua santidade - ou seja, a sua separação - o infinito não queima os olhos que a ele se dirigem. Fala, não tem o formato mitico impossível de enfrentar $e$ que manteria o eu preso dentro de suas redes invisiveis. Não é o numinoso: o eu que o aborda não é nem aniquilado ao seu contato, nem transportado para fora de si, mas permanece separado e conserva a sua autonomia" (Totalité et Infini, p. 39-40).

25 "A idéia do infinito, a relação metafisica, é o alvorecer de uma humanidade sem mitos" (Ibid., p. 75). 


\section{Linguagem e desmistificação}

A experiência com o saber racional é uma experiência que envolve a solidão de um ser separado, às voltas com a permanente possibilidade da dúvida. $\mathrm{Na}$ perspectiva levinasiana, o mundo exterior, com todas as suas formas e contornos, é um mundo que se oferece como espetáculo, como objeto de pura contemplação. Mundo silencioso, sem origem ou começo; mundo possuído pela aparência, pela ausência de palavra verdadeira; mundo sem rosto e, conseqüentemente, anárquico. Tudo se passa como se o Gênio Maligno de Descartes estivesse permanentemente escondido e pronto a manifestar-se, desestabilizando a segurança de supostas certezas, trazendo a suspeita de que os fenômenos se degradam em aparências. Para Levinas, a possibilidade da dúvida universal encontra-se presente em toda aparição, mesmo naquela de uma intuição puramente filosófica. A aparição sempre renovada do fenômeno não escapa ao equívoco, que por sua vez não cessa de gerar a dúvida. ${ }^{26}$

Por conseguinte, a característica primeira do mundo silencioso dos fatos é uma espécie de enfeitiçamento e de domínio da aparência, tal qual ocorre no mundo da magia. Nele, feiticeiras zombeteiras falam uma antilinguagem, rindo-se daqueles que buscam a saída de um labirinto. Situação constantemente abordada pelas peças de Shakespeare, em que seres que nunca se mostram diretamente, mas sempre ameaçam com um riso escarninho, denunciam uma instância intermediária entre o ilusório e o sério, lugar semelhante ao do próprio sujeito filosófico experimentando a dúvida. Riso que sempre envolve mistificação, predomínio da aparência e ausência de começo. Um mundo sem rosto é um mundo em que o sentido degradou-se em feitiçaria, onde a duplicidade é a característica primeira de um universo mistificado. Neste universo, não há palavra verdadeira, mas rimas destituídas de nexo lógico, sussurros, risos, alusões...

O conceito levinasiano da linguagem implica a possibilidade de uma quebra do feitiço de um mundo anárquico, pois falar é prestar auxilio a si mesmo, é exprimir-se, é começar. Mas o princípio não vem do eu separado; ele vem de outrem, de um rosto que se apresenta, que ensina, que torna a linguagem possível. Sem a relação com o outro, um signo não poderia aparecer a mim como um dado, como um ensinamento, como um desencantamento da aparência. A linguagem como sistema de signos pressupõe a presença de um significante que não é o significado do signo, mas "aquele que libera o signo e o oferece". ${ }^{27}$ Ao colocar em dúvida suas próprias evidências e certezas, o sujeito pensante e solitário não poderia receber um sim a partir do próprio exercício da dúvida. O movimento da dúvida é uma descida, uma queda no abismo, um retorno ao anonimato, ao ser impessoal (il y a). "Não sou eu - é Outrem que pode dizer sim."28

Sem o acolhimento de outrem, o saber não poderia começar. Sem essa presença do outro, o mundo silencioso nem mesmo poderia oferecer-se como espetáculo, como objeto de contemplação. Assim, a objetividade "se põe num discurso,

26 Cf. Totalité et infini, p. 91.

27 Ibid., p. 93.

28 Ibid., p. 94. 
numa conversa (entre-tien) que propõe o mundo. Esta proposição se mantém entre dois pontos que não constituem sistema, cosmo, totalidade."29 Portanto, é a linguagem como relação entre termos separados que torna possível a própria objetividade do objeto, sua significação. Outrem é aquele que tematiza, que pro-põe o mundo. $\mathrm{O}$ mundo nunca é um original, pois ele sempre requer o emissor do sinal, um mestre, o que ensina. Mas este ensinamento não é uma fala sobre o si mesmo, sobre uma interioridade, senão uma tematização do mundo.

A possibilidade do ensinamento põe fim à anarquia dos fatos, evita que o eu seja apenas um joguete de uma mistificação, que ele seja envolvido por uma realidade anônima, impessoal, ignorando tudo o que lhe fosse exterior. A linguagem permite que o mundo se ofereça como objeto, quebrando o feitiço da aparência e a anarquia do que não possui começo.

\section{A ética instaura a razão}

A escrita levinasiana parece, aqui, denunciar uma armadilha inerente à própria atividade teórica, aberta pela relação ética, pois na tradição ocidental a sabedoria implicada no saber será a negação da separação exigida pela idéia de infinito. A separação deveria assim integrar-se e unir-se a uma totalidade que teria 0 papel de elevar os interlocutores a um plano comum. A metafísica ocidental nega a assimetria necessária à linguagem, considerando-a um momento a ser superado, uma etapa a ser vencida. Ora, não temos aí uma permanente possibilidade de retorno ao mundo mistificado, suscetível ao charme do encantamento e da retón$\mathrm{ca}$, aberto à sedução da palavra e ao fascínio da política? Não estaria aí o perigo de uma sabedoria eminentemente humana? A sabedoria grega, afirma Levinas, está aberta à sofística. Não é por acaso que ela se coloca a serviço da força e da política na própria atividade da ciência. Assim: "Existiria na sabedoria puramente humana o poder de inverter-se em mentira e em ideologia."30

Ora, o eu cognoscente é o Mesmo, sua atividade provoca a renúncia de qualquer afirmação do Outro. Diante dele, a alteridade sempre é desmentida e vencida, e é precisamente por meio desta conquista que o idealismo não é um caso à parte na história do pensamento ocidental. Assim, a supremacia do saber, confirmada pelo idealismo, não impede que ocorra uma espécie de alienação do Mesmo no momento em que este vence a luta por seu reconhecimento ou sua primazia. Qual a origem de tal alienação? Levinas a identifica no acontecimento da Guerra e da Administração, mas também na liberdade do Mesmo, da qual curiosamente ele próprio se torna vítima e prisioneiro. ${ }^{31}$ Aprisionado e capturado pela perspectiva histórica e pelo destino nele inscritos, o Mesmo fixa-se numa trama, numa totalidade. Mas o Desejo não pode esgotar-se nesta fixidez, nesta imanência, neste envolvimento. Permanece aí o desejo de um absolutamente outro. ${ }^{32}$

\footnotetext{
29 Ibid., p. 97.

30 L'au-delà $d u$ verset - lectures et discours talmudiques. Paris: Minuit, 1982, p. 44.

31 Cf. Transcendance et Hauteur, p. 97

32 Cf. item 3.
} 
A linguagem, através da qual o Mesmo acolhe Outrem sem assimilação e sem tematização, é o acontecimento original que permite o questionamento da liberdade do saber e da violência inerente à razão. O mestre que me ensina é aquele que julga, de sua altura, a liberdade do pensamento que reduz e aprisiona o conhecido. É esta associação que desfará, talvez permanentemente, o charme de um mundo enfeitiçado de que tanto fala Levinas e, assim fazendo, colocará a justiça numa condição anterior à liberdade. A presença concreta de Outrem diz o sim necessário ao desencantamento contra o qual a ontologia não tem como defendernos, pois que se encontra ela própria aprisionada por uma clausura geradora da indiferença para com outrem. A ética instaura a razão. Nela o dizer profético liberta o logos da retórica e do fascinio da aparência que sempre ameaçam a busca da verdade. Questionar a razão é, em Levinas, uma luta para libertá-la, para desenfeitiçá-la de um sono causado pela embriaguez do círculo mágico do Mesmo, assoberbado consigo próprio e acomodado em seu repouso. O Mito que se desfez na lucidez do logos pode retornar no próprio jogo mítico do ser, eis a violência aterradora e desumana contra a qual Levinas não se cansa de lutar. A idéia de infinito dessacraliza o numinoso, abrindo a possibilidade do discurso racional. No entanto, a liberdade do Mesmo, inscrita no pensamento filosófico tradicional, não pode por si só impedir o retorno do anonimato e o silêncio de um mundo sem linguagem. O século XX manifestou este retorno de um modo paradigmático. Século de duas guerras mundiais, de extermínio, de miséria e de exclusão humana. O mundo contemporâneo é sinônimo do próprio encantamento.

\section{Em busca de um autrement qu'être}

São as conseqüências da crise da metafísica, o fiasco do Ocidente que interessam a Levinas. Ele reflete sobre o mundo devastado, caótico, enfeitiçado, entregue ao jogo como a marca mais profunda do fiasco do humano. O mundo contemporâneo seria a conseqüência mais trágica da crise do sentido.

Em um estudo de 1972, intitulado $A$ ética como transcendência e o pensamento contemporâneo, ${ }^{33}$ Levinas interpreta a condição do homem ocidental como uma presença enigmática e desconfortante em um universo que o aprisiona, mesmo depois das descobertas e das conquistas espaciais. O universo com sua imensidão, oferecido às façanhas de homens inquietos, apenas indica o aprisionamento no espaço, uma impossibilidade de sair dos limites do cosmo, isto é, de sua imanência. O mundo da técnica parece significar a extrema liberdade do homem que faz apenas a sua própria vontade, mas também a igualdade de tudo, a indiferença, a ausência total de começo e de novidade. O Mesmo convertendo-se em indiferença, aprisionando e absorvendo tudo. ${ }^{34} \mathrm{O}$ Mesmo aprisionado em si mesmo. O mundo contemporâneo é descrito como

33 Publicado em: LEVINAS, E. De Dieu qui vient à P'idée (Paris: Vrin, 1992), sob o título "Idéologie et idéalisme", p. 17-33.

34 De Dieu qui vient à l'idée, p. 31. 
"Encantamento dos lugares, hipérbole dos conceitos metafisicos, artifício da arte, exaltação das cerimônias, magia das solenidades - em toda parte suspeita-se e denuncia-se uma montagem teatral, uma transcendência de pura retórica, o jogo."35

Assim, a filosofia de Levinas caracteriza-se por uma permanente tentativa de escapar a esta conversão do sentido em jogo, do saber teórico em violência mítica, e é por isso que ela permite uma reavaliação de todo o desenvolvimento da cultura ocidental. Essa tentativa de explorar o campo de sentido da linguagem a partir da ética, da relação ao outro, torna-se tanto mais grave e atual quando reflete também sobre a crise do sentido e da cultura no mundo contemporâneo. Sua originalidade está na atenção para a possibilidade do novo, de um recomeço sem nostalgia, sem apelo ao ser. É sem dúvida uma filosofia da tensão e do risco. Acredita que um para além do $\operatorname{ser}^{36}$ possa significar e abrir uma dimensão nova para a inteligibilidade filosófica. O autrement qu'être é a primazia do Outro sobre o Mesmo, uma responsabilidade capaz de individualizar o "sujeito" sem elevá-lo à condição de um poder imperialista; ele é também a vigilância da razão despertando de uma embriaguez, de um aburguesamento. Enquanto tal, encontra-se sempre numa encruzilhada, numa linha divisória. O profetismo de uma palavra capaz de desenfeitiçar o universo sem linguagem é uma (in)condição da própria subjetividade humana, do sentido do dizer "eu", na encruzilhada do saber e de um além (au-delä) do próprio saber. Eis, para nós, o sentido e a maior dificuldade da filosofia de Levinas.

Ibid.

Cf.: LEVINAS, E. Autrement qu'être ou au-delà de I'essence. La Haye: Martinus Nijhoff, 1974. Esta obra é talvez a expressão mais acabada do pensamento de Levinas. Evitando a terminologia ontológica ainda presente em Totalité et Infini (1961), o filósofo passa a utilizar uma escrita ética estranhamente original. O Dizer é linguagem que permite descrever a subjetividade como Outro-noMesmo, como eu responsável pelo Outro antes de qualquer escolha e da própria liberdade. O sujeito é, assim, pura exposição ou suscetibilidade, é sensibilidade como Um-para-o-Outro, antes mesmo de Ser-para-Si. O Dizer vem antes do Dito, do Sistema Fechado e da Linguagem estruturada. Todo o universo da ontologia (Dito) já supōe a subjetividade como responsabilidade pelo Outro (Dizer), que sempre pode des-dizer o já dito. 